\title{
Exploring the environmental transmission electron microscope
}

Wagner, Jakob B.; Cavalca, Filippo; Damsgaard, Christian D.; Duchstein, Linus D.L.; Hansen, Thomas W.; Renu Sharma, Peter A. Crozier

\section{Published in:}

Micron

Link to article, DOI:

10.1016/j.micron.2012.02.008

Publication date:

2012

Document Version

Publisher's PDF, also known as Version of record

Link back to DTU Orbit

Citation (APA):

Wagner, J. B., Cavalca, F., Damsgaard, C. D., Duchstein, L. D. L., Hansen, T. W., \& Renu Sharma, P. A. C. (2012). Exploring the environmental transmission electron microscope. Micron, 43(11), 1169-1175.

https://doi.org/10.1016/j.micron.2012.02.008

\section{General rights}

Copyright and moral rights for the publications made accessible in the public portal are retained by the authors and/or other copyright owners and it is a condition of accessing publications that users recognise and abide by the legal requirements associated with these rights.

- Users may download and print one copy of any publication from the public portal for the purpose of private study or research.

- You may not further distribute the material or use it for any profit-making activity or commercial gain

- You may freely distribute the URL identifying the publication in the public portal 


\title{
Exploring the environmental transmission electron microscope
}

\author{
Jakob B. Wagner*, Filippo Cavalca, Christian D. Damsgaard, Linus D.L. Duchstein, Thomas W. Hansen \\ Center for Electron Nanoscopy, Technical University of Denmark, DK-2800 Kgs. Lyngby, Denmark
}

\section{A R T I C L E I N F O}

Article history:

Received 30 June 2011

Received in revised form 13 February 2012

Accepted 13 February 2012

\section{Keyword:}

In situ environmental TEM

\begin{abstract}
A B S T R A C T
The increasing interest and development in the field of in situ techniques have now reached a level where the idea of performing measurements under near realistic conditions has become feasible for transmission electron microscopy (TEM) while maintaining high spatial resolution.

In this paper, some of the opportunities that the environmental TEM (ETEM) offers when combined with other in situ techniques will be explored, directly in the microscope, by combining electron-based and photon-based techniques and phenomena. In addition, application of adjacent setups using sophisticated transfer methods for transferring the specimen between specialized in situ equipment without compromising the concept of in situ measurements will be exploited. The opportunities and techniques are illustrated by studies of materials systems of $\mathrm{Au} / \mathrm{MgO}$ and $\mathrm{Cu}_{2} \mathrm{O}$ in different gaseous environments.

(C) 2012 Elsevier Ltd. All rights reserved.
\end{abstract}

\section{Introduction}

The need for studying materials under realistic conditions is emphasized both by academic and industrial research. Acquiring highly resolved local information from materials under realistic environments by means of TEM is essential in connecting microscopic and macroscopic properties of materials. In particular the catalysis (Datye, 2003) and semiconductor (Kodambaka et al., 2007) communities have highlighted the need for investigating materials under the conditions in which they operate in order to overcome the drawbacks of post mortem studies, in which samples are transferred to microscope facilities after reactions and/or synthesis for ex situ characterization under vacuum.

Even though the capability of imaging features at elevated temperatures in non-vacuum conditions using electrons has been available for more than half a century, it is only within the last decade that commercially available TEMs have offered this option. Along with the general development in spatial resolution of TEMs, the possibility of acquiring TEM images with atomic resolution at elevated temperatures in controlled gaseous environments is now possible in several facilities around the World.

The pioneering work of Hashimoto and Naiki (1968) in the 1950 s and 1960 s resulted in the development of the first reaction specimen chamber compatible with TEM based on differential pumping. The basic ideas are still used in the high-end environmental TEMs available today, although refined by Baker and co-workers in the 1970 s primarily to study particle mobility and carbon

\footnotetext{
* Corresponding author.

E-mail address: jakob.wagner@cen.dtu.dk (J.B. Wagner).
}

filament growth (Baker and Harris, 1972; Baker et al., 1972; Baker, 1979). In present-day microscopes, the environmental cell is an integrated part of the microscope column to increase stability and thereby resolution. This type of setup allowed Boyes and Gai (1997) to demonstrate a point resolution of $0.23 \mathrm{~nm}$ in a gaseous atmosphere in 1997. Since then, the resolution has gradually been improved using field emission guns (Hansen et al., 2001, 2002; Helveg and Hansen, 2006) and aberration correctors (Hansen et al., 2010; Wagner et al., 2008). An account of recent results and performance up to the aberration correction era of environmental TEMs can be found in a review by Sharma (2005).

\section{The environmental TEM}

In general there are two approaches to perform TEM experiments in the presence of gases. These are based on a closed cell TEM holder (Creemer et al., 2008) and a differential pumping scheme (Boyes and Gai, 1997), respectively. Each has its advantages and disadvantages.

In the closed-cell approach, specially designed TEM holders enclose the specimen between two electron transparent windows (e.g. C or SiN), confining the gas within a thin slab $(10-200 \mu \mathrm{m})$ around the sample. This approach can in principle be used for both liquids and gaseous atmosphere at pressures up to $c a .1 \mathrm{bar}$ (Creemer et al., 2008; Klein et al., 2011). Besides high pressure, the main advantage of the closed cell approach is that the holder can be used in different microscopes without further modifications to the TEM column. The drawback is that the images are distorted by interaction of the electrons with the two membranes. This interaction also hinders reliable EDX spectroscopy. The specimen geometry and the field of view are usually significantly smaller than in a 


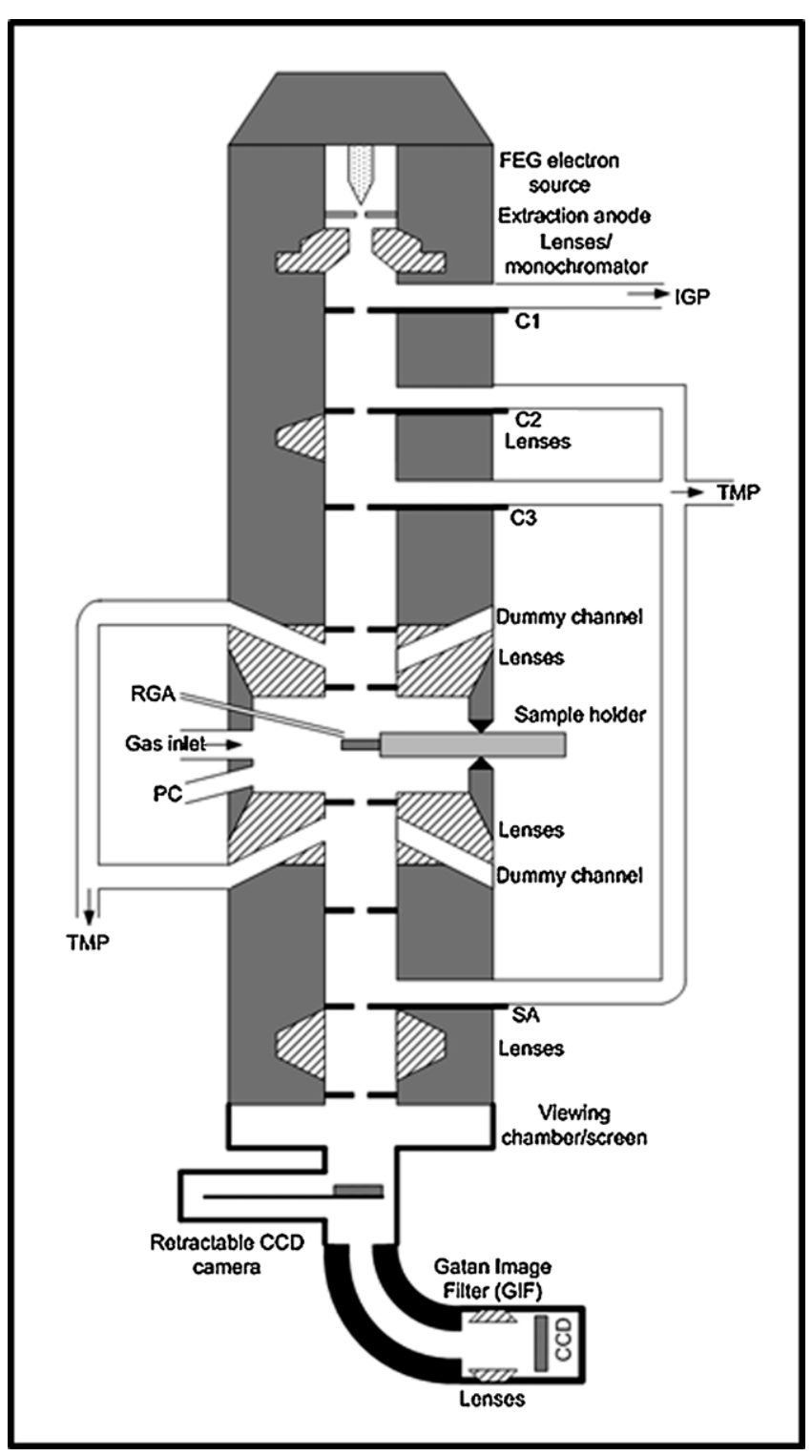

Fig. 1. Schematic diagram of a differentially pumped TEM column. FEG: field emission gun; IGP: ion getter pump; TMP: turbo molecular pump; RGA: residual gas analyzer; PC: plasma cleaner; C1: first condenser aperture; SA: selected area aperture.

conventional TEM and the setup imposes constraints on the sample geometry. As of now, the closed-cell approach provides the unique possibility to expose samples to ambient pressure (and even above) while imaging in the TEM.

In contrast to the windowed holder approach, the differential pumped TEM or environmental TEM (ETEM) tackles the problem of having a gaseous atmosphere in the vicinity of the sample by modifying the microscope column. In order to keep the high pressure pathway as small as possible, pressure limiting apertures have been inserted in the bore of the pole-pieces and additional pumping in the form of turbo molecular and ion getter pumps is used, see Fig. 1. The gas pressure, usually less than $3000 \mathrm{~Pa}$, is maintained by a controlled flow directly into the pole piece gap. Using this type of set-up, Yoshida and co-workers were able to demonstrate lattice-fringe images of transition metals at pressures up to $2 \times 10^{3} \mathrm{~Pa}$ (Yoshida et al., 2007). As a result, all commercially available TEM holders can be used without modifications. That, together with custom-built TEM holders, paves the way for various kinds of in situ experiments traditionally performed in conventional TEMs,

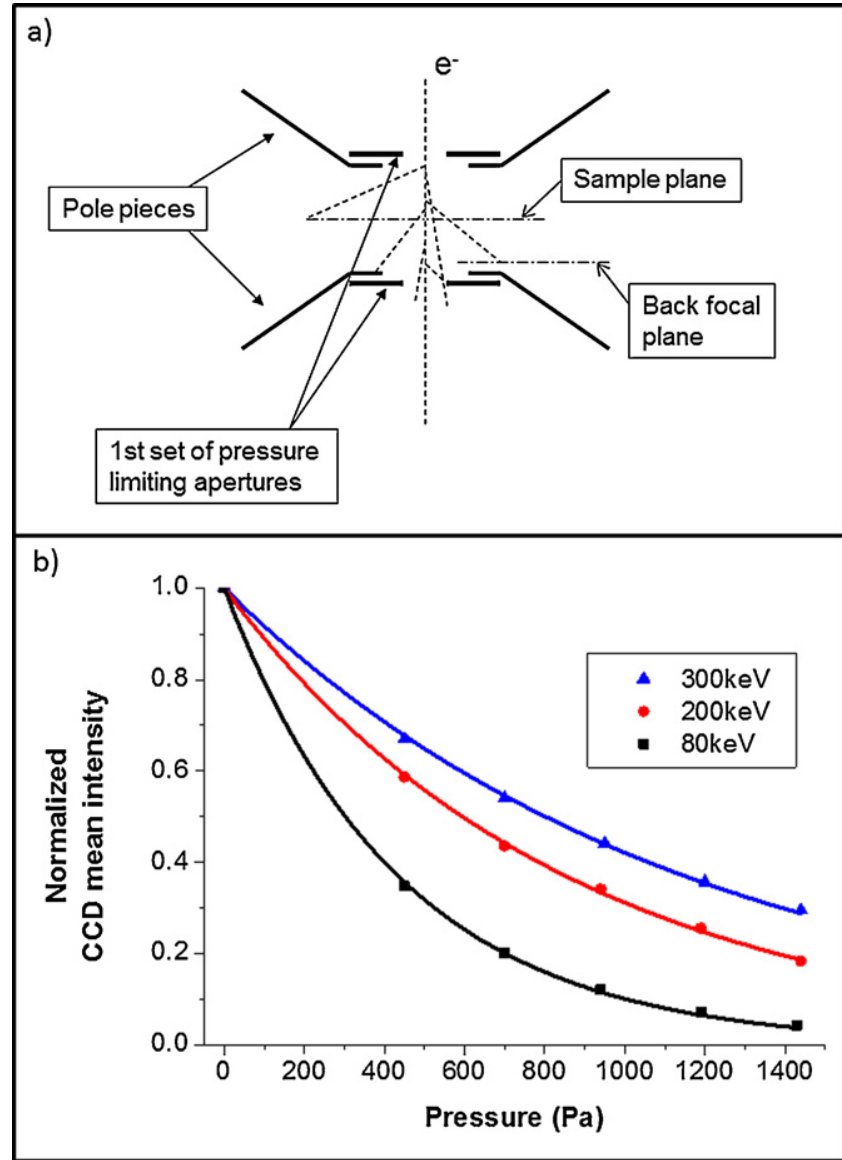

Fig. 2. Effect of scattering of electrons on gas molecules in a differential pumped ETEM. (a) Scattering of electrons on gas molecules (indicated by hatched lines) takes mainly place between the first set of pressure limiting apertures, which extend the focal length of the objective lens. (b) Normalized image intensity (without a specimen present) measured on a pre-GIF Ultrascan CCD camera, plotted as a function of gas pressure for Ar at three different acceleration voltages. The data points have been fitted to exponential functions.

to be performed in a controlled gaseous environment while maintaining a high spatial resolution.

Several factors have to be taken into account when combining high energy electrons with a gaseous environment (Hansen et al., 2010). The fast electrons are scattered both elastically and inelastically by the gas molecules resulting in distortions of the electron wave both above and below the sample, thus altering the incoming and the exit wave carrying the image information. Furthermore, the interaction between the fast electrons and gas molecules lead to ionization of the gas molecules.

\section{Interaction of the electron beam with gas molecules}

As described above, electrons should traverse the shortest possible path through gas in order to avoid heavy scattering. In aberration corrected ETEMs the pole piece gap and thereby the distance between the first pair of pressure limiting apertures are on the order of $7 \mathrm{~mm}$ (Hansen et al., 2010). If the gas molecules contained in this volume at $1000 \mathrm{~Pa}$ were to be compressed to a density comparable to that of a solid, the resulting solid would be an approximately $10 \mathrm{~nm}$ thick slab. However, scattering on gas molecules takes place not only in the eucentric plane as for conventional samples, but in the entire pole piece gap including at the back focal plane as indicated in Fig. 2a, which implies that the scattering geometry becomes ill-defined in relation to the objective lens and the rest of the imaging lens system. The rather complex 
Table 1

Cross sections and mean free path of interaction between fast electrons and gas molecules estimated from fitting intensity-loss measurements in a FEI Titan ST ETEM.

\begin{tabular}{llc}
\hline & $\sigma\left[\mathrm{m}^{2}\right]$ & $\lambda(500 \mathrm{~Pa})\left[10^{-3} \mathrm{~m}\right]$ \\
\hline $80 \mathrm{kV}, \mathrm{H}_{2}$ & $1.8 \times 10^{-22}$ & 45.9 \\
$80 \mathrm{kV}, \mathrm{He}$ & $9.7 \times 10^{-23}$ & 85.5 \\
$80 \mathrm{kV}, \mathrm{N}_{2}$ & $8.9 \times 10^{-22}$ & 9.3 \\
$80 \mathrm{kV}, \mathrm{O}_{2}$ & $9.1 \times 10^{-22}$ & 9.1 \\
$80 \mathrm{kV}, \mathrm{Ar}$ & $1.3 \times 10^{-21}$ & 6.6 \\
$200 \mathrm{kV}, \mathrm{N}_{2}$ & $4.1 \times 10^{-22}$ & 20.2 \\
$200 \mathrm{kV}, \mathrm{O}_{2}$ & $4.1 \times 10^{-22}$ & 20.1 \\
$200 \mathrm{kV}, \mathrm{Ar}$ & $6.0 \times 10^{-22}$ & 13.8 \\
$300 \mathrm{kV}, \mathrm{N}_{2}$ & $3.2 \times 10^{-22}$ & 26.2 \\
$300 \mathrm{kV}, \mathrm{O}_{2}$ & $3.0 \times 10^{-22}$ & 27.7 \\
$300 \mathrm{kV}, \mathrm{Ar}$ & $4.5 \times 10^{-22}$ & 18.5 \\
\hline
\end{tabular}

trajectories which the scattered electron now follow leads to a loss of intensity in the final image as electrons being scattered above and below the sample are captured by apertures (or the column itself). Fig. 2b shows the normalized CCD mean intensity of the electron beam without any solid sample in the field of view as a function of Ar pressure and primary electron energy. The loss of intensity is severe at higher pressures. In $1400 \mathrm{~Pa}$ Ar more than half of the intensity is lost when imaging with $300 \mathrm{keV}$ electrons, and more than $95 \%$ is lost when using $80 \mathrm{keV}$ electrons. The intensity loss curve plotted in Fig. 2b can be well approximated by the following exponential function:

$\frac{I}{I_{0}}=e^{-p / t}=e^{-x / \lambda}$,

where $x$ denotes the distance from the upper pole piece (defining the start of the high pressure zone) and $\lambda$ is the mean free path given by:

$\lambda=\frac{1}{\sigma n}=\frac{R T}{\sigma P}$,

where $P$ is the pressure and $T$ is the temperature. Under the conditions in the ETEM, the gas phase can be approximated as an ideal gas. Using the equations described above we have fitted intensity-loss plots for different gas species acquired using different acceleration voltages. The estimated cross-sections and mean free paths are summarized in Table 1 . In general we observe a greater loss for lower acceleration voltages and heavier gas species consistent with larger scattering cross-sections (Hansen et al., 2010).

In order to gain insight into the energy distribution of the scattered electrons, energy resolved diffraction experiments are performed in situ in the presence of gas. To project the electrons scattered above or below the eucentric plane onto the object plane of the imaging lens system, the objective lens was turned off and the microscope operated in Lorentz mode. This way the scattering geometry between the pole pieces is better defined as the electron-gas scattering is taking place outside the field of the magnetic lenses (in contrast to conventional TEM where the objective lens is turned on). The cut-off angle in Lorentz-mode of a FEI Titan ETEM is defined by the second set of pressure limiting apertures and changes only slightly as a function of scattering center position over the range where most electron-gas scattering takes place between the first set of pressure limiting apertures as sketched in Fig. 3a. In the present case the cut-off has been measured to be $10 \mathrm{mrad}( \pm 1 \mathrm{mrad})$. In Fig. 3b energy-loss spectra of $1100 \mathrm{~Pa}$ Ar gas are shown at different scattering angles. The spectra are extracted from rotationally averaged low-angle diffraction patterns acquired as a function of energy-loss using a $0.3 \mathrm{eV}$ energy-selecting slit width and an acceleration voltage of $300 \mathrm{kV}$. The zero-loss peak is normalized in the plot. The ratio between the zero loss peak and the inelastically scattered electrons are observed to decrease with scattering angle. This is not surprising as the zero loss consists of both non-scattered electrons and elastically scattered electrons. In general, multiple scattering on the gas molecules can be neglected at these pressures as the mean free path is considerably larger than the high pressure region, see Table 1.

In Fig. 3c the low-loss region of Ar gas is plotted. The spectra have been rescaled to align the intensity of the feature at $12 \mathrm{eV}$. As observed, the fine structure depends on the scattering angle which has to be considered when studying e.g. plasmons of solid samples in the presence of gas as the gas spectrum will be convoluted onto the solid phase spectrum.

The core loss signal acquired by electron energy-loss spectroscopy (EELS) of gases is an excellent tool for quantifying the gas composition in the vicinity of the sample when using gas mixtures in the ETEM as shown by Crozier and Chenna (2011). Recently, Crozier (2011) has shown the possibility of measuring reactivity of catalysts using EELS and thereby directly linking structural information extracted from imaging to activity of catalysts.

\subsection{Ionization of gas molecules}

The current density in the electron beam in a TEM can be high and is known to be able to modify the observed sample in unwanted ways. In general two types of beam damage are considered in the TEM: Knock-on damage and radiolysis. The former is caused by displacement of atoms in the sample by momentum transfer from fast primary electrons to atoms in the sample. Usually, this can be minimized by lowering the energy of the electron beam (Egerton et al., 2010; Smith and Luzzi, 2001). Radiolysis is caused by fast electrons modifying the chemical bonds in the sample, leading to changes. This type of damage is usually larger for lower electron beam energies due to the larger interaction cross section. Examples of beam-induced chemistry can be found in the electron beam induced reduction of molybdenum and vanadium oxides (Su et al., 2001; Wang et al., 2004).

Interaction between electrons and gas molecules leads to ionization thus increasing their reactivity. In other words, in addition to the usual beam effects observed in high vacuum, gases that are normally inert can be reactive when ionized by the electron beam. Therefore it is very important to perform the ETEM experiments as a function of beam current density to explore the effects of ionized gas molecules on the sample.

The combination of the electron beam and gas molecules can be studied in detail and exploited (van Dorp et al., 2011). As an example we have studied the behavior of MgO smoke particles covered with Au nanoparticles in the presence of water vapor in situ in the microscope. $\mathrm{MgO}$ smoke particles produced by ignition of an $\mathrm{Mg}$ metal ribbon form close-to-perfect cubes exposing the $\operatorname{MgO}\left\{\begin{array}{lll}1 & 0 & 0\end{array}\right\}$ surfaces. Au is sputter-coated onto the cubes forming 2-6 nm epitaxially oriented Au nanoparticles. Pure MgO-smoke particles are known to hydroxylate under electron irradiation in the presence of water (Gajdardziska-Josifovska and Sharma, 2005). The electron beam is thought to modify the perfect $\{100\}$ surfaces of the $\mathrm{MgO}$ cubes, which are otherwise resistant to hydroxylation. MgO species $\left(\mathrm{Mg}^{+},(\mathrm{MgO})^{+}\right)$are mobile on the surface of the cubes as a result of the energy transferred from both primary and secondary electrons (Kizuka, 2001) creating steps and kinks on the MgO $\left\{\begin{array}{lll}1 & 0 & 0\end{array}\right\}$ surfaces. Fig. 4 summarizes our findings on the effect of electron dose and water vapor pressure in the vicinity of the sample. All experiments are performed at room temperature. The images are frames extracted from movies after approximately 30 min exposure in each case. At low pressure $\left(P=10^{-5} \mathrm{~Pa}\right)$ and relative low electron dose rate $\left(10^{-15} \mathrm{~A} / \mathrm{nm}^{2}\right)$ the surface mobility is observed to be relatively small. In conventional high-vacuum TEM mode (including the use of a cold trap to minimize the water vapor pressure) the column base-pressure is $c a .10^{-5} \mathrm{~Pa}$. Increasing the electron dose 


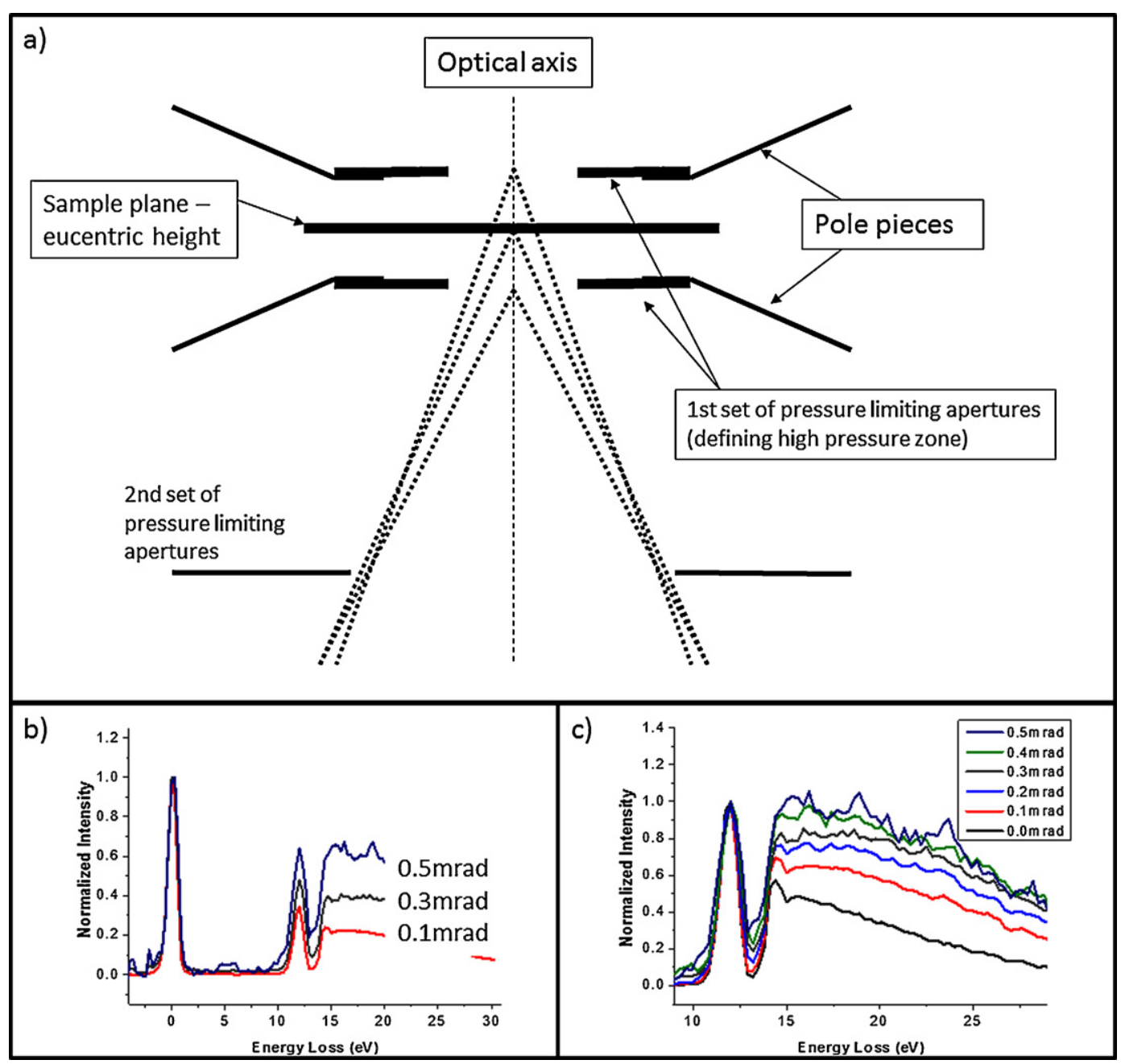

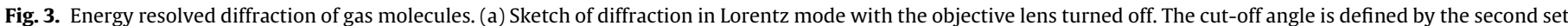

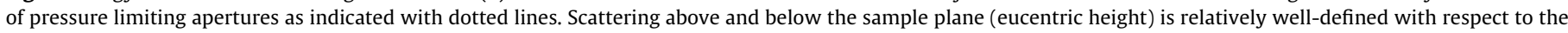

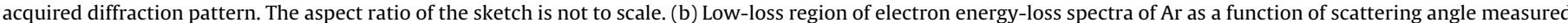

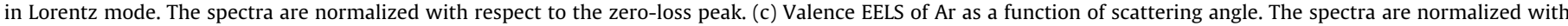
respect to the feature at $12 \mathrm{eV}$. The spectra in (b) and (c) are retrieved from energy-filtered diffraction patterns, see text for details.

or the pressure by leaking in water vapor, increases the mobility of $\mathrm{MgO}$ species on the surface resulting in the formation of kinks and steps. At increasing water vapor pressure the species diffusing at the $\mathrm{MgO}$ surfaces start to accumulate at the $\mathrm{Au} / \mathrm{MgO}$ interface. At relatively high electron dose rate $\left(10^{-14} \mathrm{~A} / \mathrm{nm}^{2}\right)$ and a pressure of $10^{-4} \mathrm{~Pa}$ pillars grow from the cubes apparently catalyzed by the $\mathrm{Au}$ nanoparticles. Au-catalyzed $\mathrm{MgO}$ pillar growth has been reported earlier (Ajayan and Marks, 1989; Nasibulin et al., 2010), but in the present study, the effect of the environment has been addressed in greater detail. Even a low partial pressure of water vapor $\left(10^{-5} \mathrm{~Pa}\right)$ has an apparent effect on surface specie mobility in the Au/MgO system.

The $\mathrm{Au} / \mathrm{MgO}$ interface is thought to act as a collection point (due to negatively charged metal particles) where the highly mobile $\mathrm{MgO}$ species are trapped and recrystallize in pillars. The presence of water species in the surrounding environment influences the charge transfer in the system changing the overall energy landscape. The change in behavior of the system in the presence of water vapor under electron beam irradiation illustrates the necessity for addressing the additional energy and radicals introduced when dealing with gases, even at room temperature. The thresholds of these beam- and gas-induced effects are strongly dependent on the material system and have to be studied systematically in each case.

\section{Combining electrons and visible light}

Photocatalysis is experiencing considerable interest due to the possibility of harvesting solar energy and storing it in chemical bonds that can be used as energy carriers. The benefit of such an approach is that existing infrastructure for energy distribution can be used for fuels produced from a sustainable resource.

In order to study photocatalysts under working conditions, a holder capable of exposing a sample to visible light in situ during gas exposure in the ETEM has been developed (Cavalca et al., 2012). Fig. 5 shows the illuminating holder together with a sketch of its configuration. The holder is developed to be compatible with different TEMs to increase operational flexibility. Furthermore, the laser light source is made interchangeable to cover a wide spectrum of wavelengths stretching from the UV and covering the entire visible range with high transmittance. In this relatively simple set-up, the TEM grid has to be bent in order for the light to illuminate the specimen. The second generation of the holder which is currently under development will incorporate mirrors to circumvent this problem.

Cuprous oxide $\left(\mathrm{Cu}_{2} \mathrm{O}\right)$ is a photocatalyst for water splitting under visible light (Hara et al., 1998). However, in aqueous environments it undergoes photodegradation (Nagasubramanian et al., 1981). In order to study the photodegradation process, $\mathrm{Cu}_{2} \mathrm{O}$ nanocubes were synthesized and loaded onto a gold TEM grid 


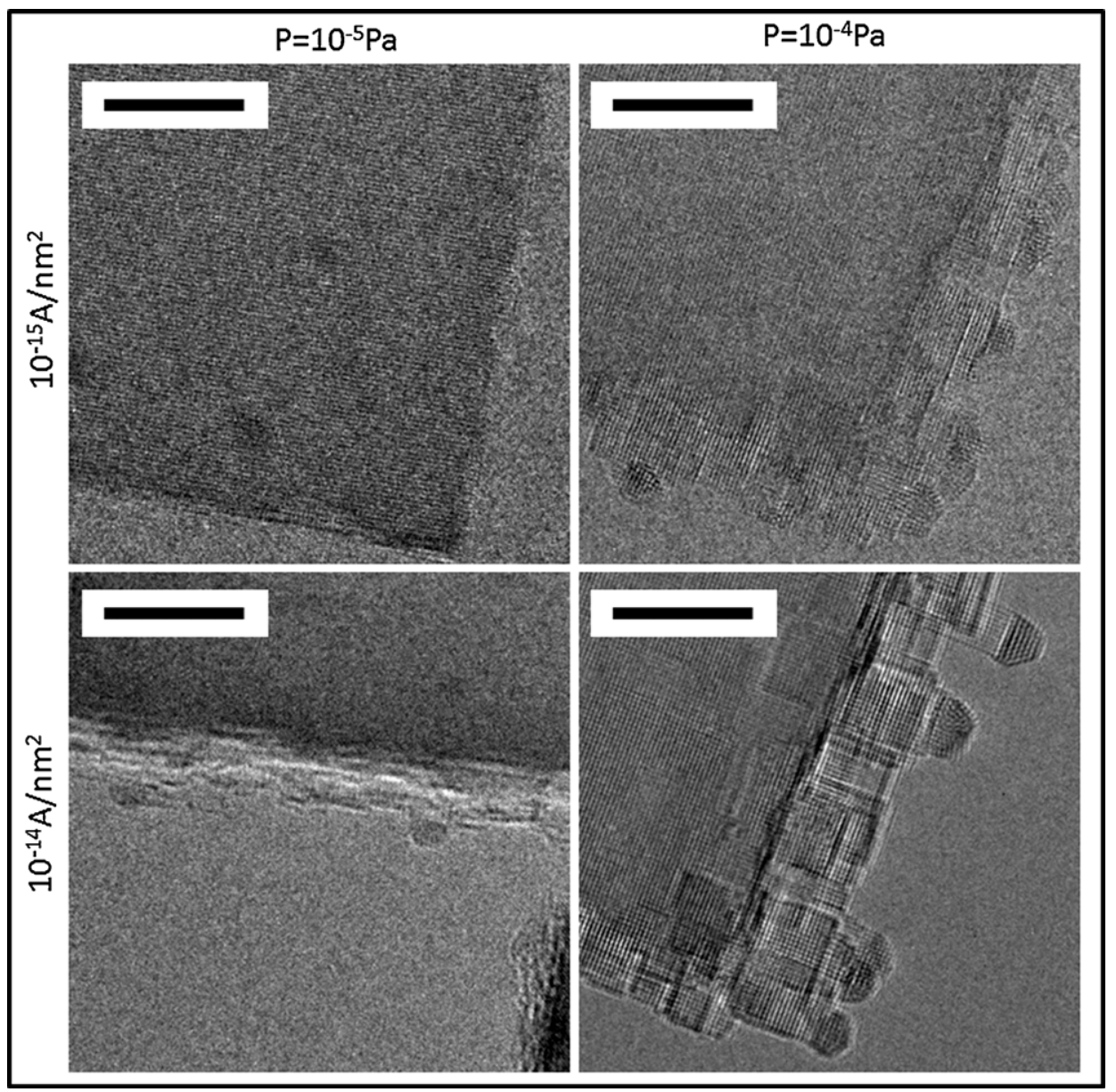

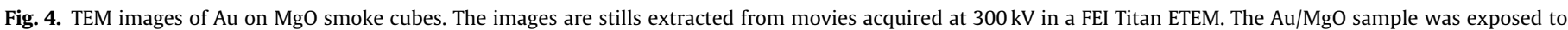
different electron dose rates $\left(10^{-15} \mathrm{~A} / \mathrm{nm}^{2}\right.$ and $\left.10^{-14} \mathrm{~A} / \mathrm{nm}^{2}\right)$ at different pressures $\left(10^{-5} \mathrm{~Pa}\right.$ and $\left.10^{-4} \mathrm{~Pa}\right)$ for approximately $30 \mathrm{~min}$ in each case. The scale bars are $5 \mathrm{~nm}$.

and mounted in the TEM illumination holder to monitor the phenomenon in situ. In Fig. 6a, a $\mathrm{Cu}_{2} \mathrm{O}$ nanocube is imaged before and after illumination with light $(\lambda=405 \mathrm{~nm})$ in $500 \mathrm{~Pa}$ of $\mathrm{H}_{2} \mathrm{O}$ for $3 \mathrm{~h}$.

One of the challenges when studying the effects of visible light in the electron microscope is to differentiate between the effect of the visible light and of the high-energy electron beam. The photon energy density produced by the laser diode on the sample in this experiment is approximately six orders of magnitude lower than that of the electron beam.

As a result of the high energy density of the electron beam, the $\mathrm{Cu}_{2} \mathrm{O}$ cubes undergo rapid degradation when exposed to water in the presence of the electron beam. In contrast, the cubes are stable under the electron beam in vacuum conditions. Time-resolved studies of the degradation process are performed by imaging the cubes using the electron beam in vacuum and blanking the electron beam during exposure to water and visible light.

In Fig. 6a, a $\mathrm{Cu}_{2} \mathrm{O}$ nanocube is imaged before and after illumination with light $(\lambda=405 \mathrm{~nm})$ in $500 \mathrm{~Pa}$ of $\mathrm{H}_{2} \mathrm{O}$ for $3 \mathrm{~h}$. The degradation of the $\mathrm{Cu}_{2} \mathrm{O}$ cubes is seen as morphology changes and formation of smaller particles nearby on the support (amorphous carbon). Furthermore a reduction of the $\mathrm{Cu}_{2} \mathrm{O}$ is observed by means of EELS (Wagner et al., 2003). Fig. 6b shows the spectra before and after the sample has been illuminated in the presence of water vapor. From the fine structure of the $\mathrm{Cu} \mathrm{L}_{2,3}$ edge it is observed that the $\mathrm{Cu}_{2} \mathrm{O}$ is fully reduced during the reaction. To be able to follow the degradation over time, a 'stop-and-go'-type experiment has to be performed. This means that the gas has to be pumped out of the microscope column before exposing the sample to the electron beam for acquisition of images. This type of quasi in situ experiments is necessary to avoid the modification of the sample by the electron beam. Even though the structural information is not retrieved during exposure to light, the sample has been kept under inert gas conditions and in the same set-up and position making it straightforward to track the same area and particles during the extended series of exposures.

\section{The value of complementary experiments - bridging gaps}

As the working conditions of a given sample are usually not compatible with the conditions obtainable using in situ techniques, the environment has to be modified from the working conditions of the material. These include sample geometry, gas pressure, gas composition etc.

As discussed above, environmental studies can be performed in an ETEM with the use of conventional sample holders (Hansen et al., 2001; Helveg et al., 2004; Kim et al., 2010; Simonsen et al., 2010) or in a traditional TEM by use of a dedicated sample holder with a high pressure cell (Creemer et al., 2008). In both cases the setup defines the boundary conditions regarding gas, pressure and temperature. In most cases these conditions are far from the working conditions of e.g. heterogeneous catalysis but also far from more model-based research in the UHV regime used in surface science studies. Our efforts focus on bridging these gaps not only by using dedicated sample holders and microscopes but also by establishing in situ sample transfer to complementary measurement techniques. 


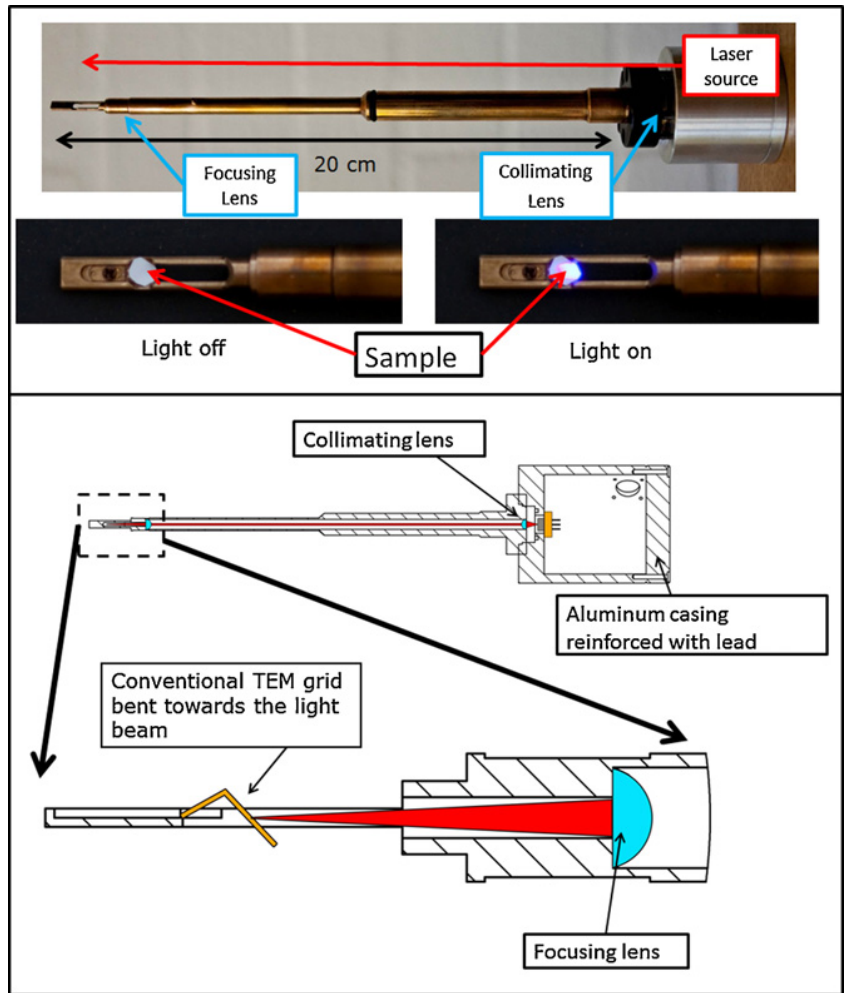

Fig. 5. TEM holder for illuminating light in situ. (a) Photograph of the holder. The illuminated area is approximately $2 \mathrm{~mm}$ in diameter. (b) Sketch of the illumination holder (with a close-up of the sample area) showing the collimating lens, the focusing lens and the sample geometry.

ETEM depends on complementary experiments and characterization techniques. Normally, this is done in parallel with experiments separated in time and space (Hansen et al., 2002) or mimicking a reactor bed by changing the feed gas composition according to reactivity and conversion measured in dedicated reactor set-ups (Chenna et al., 2011). Although this approach has proven useful, it will be beneficial to take it one step further and use the same sample geometry in all complementary experimental studies and thereby (in principle) using the same sample transferred under reactions conditions.

Dedicated transfer holders are used to transfer catalyst samples between reactor set-ups and TEM facilities (Kooyman et al., 2001). This is usually done at room temperature in inert atmosphere by loading the sample in the TEM holder in a glove box and sealing the holder. However, the criteria for such an in situ transfer concept are that the transfer environment is controlled. This could either be in vacuum or a in an inert or active gas composition at a given temperature and pressure. A full palette of measurement techniques capable of in situ sample transfer could be performed on samples sensitive to pressure, atmosphere, and temperature without sample contamination between measurements. Following this approach TEM characterization can be used to study individual synthesis steps of nanoparticle catalysts by in situ transfer of the sample between a synthesis set-up and a TEM without breaking vacuum or changing gas.

As transmission electron microscopy is a time consuming characterization technique requiring human interaction, following sample evolution over extended periods of time, say, days or weeks, is usually impractical. In the microscope, rapid aging experiments are thus typically used where the conditions can be different from those used industrially. Using inert transfer between in situ characterization tools is better suited for long term experiments, e.g. in situ $\mathrm{XRD}$, and allows intermittent inspection of materials transferred to
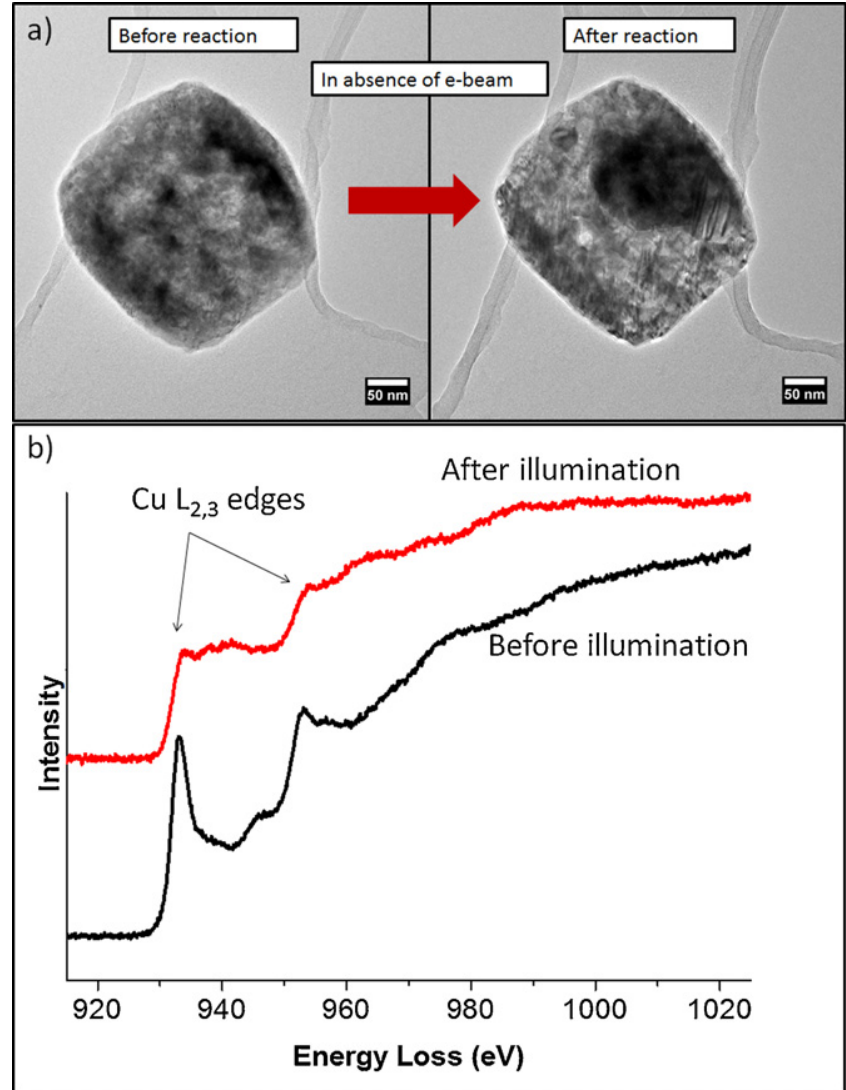

Fig. 6. Reduction of $\mathrm{Cu}_{2} \mathrm{O}$ cubes during exposure to water vapor under illumination of visible light $\left(\lambda=405 \mathrm{~nm}\right.$ ). (a) $\mathrm{Cu}_{2} \mathrm{O}$ cubes before and after $3 \mathrm{~h}$ of illumination in the presence of $500 \mathrm{~Pa}$ water vapor (electron beam blanked). (b) The fine structure of the $\mathrm{Cu} \mathrm{L}_{2,3}$ ionization edge acquired from the cubes before and after the visible light illumination.

the ETEM without changing the environment. Such experiments could include aging of catalysts in the in situ XRD under operando conditions and under continuous monitoring. Local information can be extracted by transfer to the ETEM facility inertly at various stages of the aging process while only varying the pressure. Other experiments could be catalysts regeneration including calcination and re-reduction steps.

\section{Conclusion (outlook)}

In situ environmental transmission electron microscopy has come a long way since the pioneering work of Hashimoto and Naiki (1968) and Baker and Harris (1972). With the recent development in hardware (e.g. aberration correction) and methods for elucidating the experiments performed in the ETEM, we are approaching an era where ETEM is to be considered established and capable of offering unique structural information under in situ conditions. Combining in situ techniques in complementary and even parallel experiments will take materials science to the next level.

\section{Acknowledgments}

The A.P. Møller and Chastine Mc-Kinney Møller Foundation is gratefully acknowledged for their contribution toward the establishment of the Center for Electron Nanoscopy in the Technical University of Denmark. We also acknowledge the funding by the Danish Ministry of Science and Technology through the Catalysis for Sustainable Energy (CASE) initiative. 


\section{References}

Ajayan, P.M., Marks, L.D., 1989. Experimental evidence for quasimelting in small particles. Phys. Rev. Lett. 63, 279.

Baker, R.T.K., 1979. In situ electron-microscopy studies of catalyst particle behavior. Catal. Rev. 19, 161

Baker, R.T.K., Harris, P.S., 1972. Controlled atmosphere electron-microscopy. J. Phys. E 5, 793.

Baker, R.T.K., Feates, F.S., Harris, P.S., 1972. Continuous electron-microscopic observation of carbonaceous deposits formed on graphite and silica surfaces. Carbon $10,93$.

Boyes, E.D., Gai, P.L., 1997. Environmental high resolution electron microscopy and applications to chemical science. Ultramicroscopy 67, 219.

Cavalca, F., Laursen, A.B., Kardynal, B.E., Dunin-Borkowski, R.E., Dahl, S., Wagner, J.B., Hansen, T.W., 2012. In situ transmission electron microscopy of light-induced photocatalytic reactions. Nanotechnology 23, 075705.

Chenna, S., Banerjee, R., Crozier, P.A., 2011. Atomic-scale observation of the Ni activation process for partial oxidation of methane using in situ environmental TEM. ChemCatChem 3, 1051.

Creemer, J.F., Helveg, S., Hoveling, G.H., Ullmann, S., Molenbroek, A.M., Sarro, P.M., Zandbergen, H.W., 2008. Atomic-scale electron microscopy at ambient pressure. Ultramicroscopy 108, 993.

Crozier, P.A., 2011. Private communication.

Crozier, P.A., Chenna, S., 2011. In situ analysis of gas composition by electron energy-loss spectroscopy for environmental transmission electron microscopy. Ultramicroscopy $111,177$.

Datye, A.K., 2003. Electron microscopy of catalysts:recent achievements and future prospects. J. Catal. 216, 144.

Egerton, R.F., McLeod, R., Wang, F., Malac, M., 2010. Basic questions related to electron-induced sputtering in the TEM. Ultramicroscopy 110, 991.

Gajdardziska-Josifovska, M., Sharma, R., 2005. Interaction of oxide surfaces with water: environmental transmission electron microscopy of MgO hydroxylation. Microsc. Microanal. 11, 524.

Hansen, T.W., Wagner, J.B., Hansen, P.L., Dahl, S., Topsøe, H., Jacobsen, C.J.H., 2001. Atomic-resolution in situ transmission electron microscopy of a promoter of a heterogeneous catalyst. Science 294, 1508.

Hansen, P.L., Wagner, J.B., Helveg, S., Rostrup-Nielsen, J.R., Clausen, B.S., Topsøe, H., 2002. Atom-resolved imaging of dynamic shape changes in supported copper nanocrystals. Science 295, 2053.

Hansen, T.W., Wagner, J.B., Dunin-Borkowski, R.E., 2010. Aberration corrected and monochromated environmental transmission electron microscopy: challenges and prospects for materials science. Mater. Sci. Technol. 26, 1338.

Hara, M., Kondo, T., Komoda, M., Ikeda, S., Shinohara, K., Tanaka, A., Kondo, J.N., Domen, K., 1998. $\mathrm{Cu}_{2} \mathrm{O}$ as a photocatalyst for overall water splitting under visible light irradiation. Chem. Commun. 2, 357.

Hashimoto, H., Naiki, T., 1968. High temperature gas reaction specimen chamber for an electron microscope. Jpn. J. Appl. Phys. 7, 946.
Helveg, S., Hansen, P.L., 2006. Atomic-scale studies of metallic nanocluster catalysts by in situ high-resolution transmission electron microscopy. Catal. Today 111 68.

Helveg, S., Lopez-Cartes, C., Sehested, J., Hansen, P.L., Clausen, B.S., Rostrup-Nielsen, J.R., Abild-Pedersen, F., Nørskov, J.K., 2004. Atomic-scale imaging of carbon nanofibre growth. Nature 427, 426.

Kim, S.M., Pint, C.L., Amama, P.B., Zakharov, D.N., Hauge, R.H., Maruyama, B., Stach, E.A., 2010. Evolution in catalyst morphology leads to carbon nanotube termination. J. Phys. Chem. Lett. 1, 918.

Kizuka, T., 2001. Formation and structural evolution of magnesium oxide clusters under electron irradiation. Jpn. J. Appl. Phys. 40, L1061.

Klein, K.L., Anderson, I.M., De Jonge, N., 2011. Transmission electron microscopy with a liquid flow cell. Transmission electron microscopy with a liquid flow cell. J. Microsc. Oxford 242, 117.

Kodambaka, S., Tersoff, J., Reuter, M.C., Ross, F.M., 2007. Germanium nanowire growth below the eutectic temperature. Science 316, 729.

Kooyman, P.J., Hensen, E.J.M., De Jong, A.M., Niemantsverdriet, J.W., Van Veen, J.A.R., 2001. The observation of nanometer-sized entities in sulphided Mo-based catalysts on various supports. Catal. Lett. 74, 49.

Nagasubramanian, G., Gioda, A.S., Bard, A.J., 1981. Photoelectrochemical behavior of p-type $\mathrm{Cu}_{2} \mathrm{O}$ in acetonitrile solutions. J. Electrochem. Soc. 128, 2158.

Nasibulin, A.G., Sun, L.T., Hamalainen, S., Shandakov, S.D., Banhart, F., Kauppinen, E.I., 2010. In situ TEM observation of MgO nanorod growth. Cryst. Growth Des. $10,414$.

Sharma, R., 2005. An environmental transmission electron microscope for in situ synthesis and characterization of nanomaterials. J. Mater. Res. 20, 1695

Simonsen, S.B., Chorkendorff, I., Dahl, S., Skoglundh, M., Sehested, J., Helveg, S., 2010 Direct observations of oxygen-induced platinum nanoparticle ripening studied by in situ TEM. J. Am. Chem. Soc. 132, 7968.

Smith, B.W., Luzzi, D.E., 2001. Electron irradiation effects in single wall carbon nanotubes. J. Appl. Phys. 90, 3509.

Su, D.S., Wieske, M., Beckmann, E., Blume, A., Mestl, G., Schlögl, R., 2001. Electron beam induced reduction of $\mathrm{V}_{2} \mathrm{O}_{5}$ studied by analytical electron microscopy. Catal. Lett. 75, 81 .

van Dorp, W.F., Lazic, I., Beyer, A., Golzhauser, A., Wagner, J.B., Hansen, T.W., Hagen, C.W., 2011. Ultrahigh resolution focused electron beam induced processing: the effect of substrate thickness. Nanotechology 22, 155303.

Wagner, J.B., Hansen, P.L., Molenbroek, A.M., Topsøe, H., Clausen, B.S., Helveg, S., 2003. In situ electron energy loss spectroscopy studies of gas-dependent metal-support interactions in $\mathrm{Cu} / \mathrm{ZnO}$ catalysts. J. Phys. Chem. B 107, 7753.

Wagner, J.B., Jinschek, J.R., Hansen, T.W., Boothroyd, C.B., Dunin-Borkowski, R.E., 2008. In situ HRTEM - image corrected and monochromated Titan equipped with environmental cell. In: Proceedings of EMC2008, 14th European Microscopy Congress, vol. 1, p. 509.

Wang, D., Su, D.S., Schlögl, R., 2004. Electron beam induced transformation of $\mathrm{MoO}_{3}$ to $\mathrm{MoO}_{2}$ and a new phase MoO. Z. Anorg. Allg. Chem. 630, 1007.

Yoshida, H., Uchiyama, T., de Moor, M., Stekelenburg, M., Takeda, S., 2007. In situ ETEM analysis of growth mechanism of carbon nanotubes. Microsc. Microanal. 13 (Suppl. 02), 712. 